\title{
Pedestrian injuries in children: who is most at risk?
}

\author{
Xun Yi Jasmine Feng ${ }^{1}$, BSc, Shireen Anne $\underline{N a h}^{1}$, MBBS, MRCSE, York Tien Lee ${ }^{1}$, MBBS, MRCSE, Yea-Chyi $\underline{\operatorname{Lin}}^{1}$, MD, MRCSE,
} Li Wei Chiang $^{1}$, MBBS, MRCSE

INTRODUCTION This study evaluates the demographics of paediatric pedestrian injuries with the aim of identifying the group of children who is most vulnerable and the risk factors for major trauma (MT).

METHODS Data was extracted from the integrated trauma system of a regional paediatric referral hospital. All paediatric cases involving road traffic accidents from January 2011 to December 2013 were studied. Demographics, injury mechanism, treatment and outcome were evaluated. Patients were categorised as MT or non-MT (NMT) based on their Injury Severity Score, admission to the intensive care unit, type of surgery (e.g. life/limb-saving) and death. Data analysis was done using nonparametric tests and Fisher's exact test.

RESULTS A total of 261 children were admitted for pedestrian injuries during the study period. The median age was ten years (range 14 months-16 years) and the median weight was 42.4 (range 8.6-93.7) kg. Half (i.e. 50.2\%) of the children were primary-schoolers. The majority of the accidents occurred on roads (i.e. 83.1\%), between 12 pm and 6 pm (i.e. 52.8\%). Among the 261 children, 177 (67.8\%) were unaccompanied by an adult at the time of the accident; $17(6.5 \%)$ children sustained MT, while $244(93.5 \%)$ suffered NMT. MT patients were more likely to have lost consciousness $(p<0.001)$ and been flung $(p=0.001)$.

CONCLUSION Most paediatric pedestrian injuries involved primary-schoolers walking home from school unaccompanied by adults. This information should inform future road safety campaigns. Being flung and loss of consciousness predicted MT in children who sustained pedestrian injuries.

Keywords: child, injury, paediatric, pedestrian, trauma

\section{INTRODUCTION}

Pedestrian injuries are a significant contributor to paediatric mortality and disability in urban societies. Due to the high population density (i.e. 7,422 persons per $\mathrm{km}^{2}$ ) in Singapore, residential areas and commercial districts are in close proximity. This, coupled with Singapore's extensive traffic infrastructure, constantly exposes children to dangers on the road and increases their risk of road traffic accidents (RTAs). In our earlier review on the local epidemiology of paediatric trauma, we found that, although falls were the most common injury mechanism, RTAs were the most frequent cause of moderate to severe injuries in children. ${ }^{(1)}$ Furthermore, due to the young age of the victims and their possible severe morbidity, the burden of care imposed on society and the families of these children should not be underestimated.

In the literature, most of the studies on RTAs involving children focus on Western societies; ${ }^{(2-6)}$ however, reports from our region are lacking. Thus, the aim of the present study was to identify the group of children who is at the highest risk of being involved in an RTA as a pedestrian, as well as the factors associated with major trauma (MT). This would allow future road safety campaigns to be tailored to our population. In addition, the identification of MT risk factors would facilitate the triage of these patients.

\section{METHODS}

Data for this study was obtained from the trauma registry of KK Women's and Children's Hospital, Singapore. All children aged 16 years and younger who were admitted to the hospital from January 2011 to December 2013 with injuries sustained as pedestrians in an RTA were recruited into this study. The injuries were coded according to the Abbreviated Injury Scale by a trauma coordinator accredited by the Association for the Advancement of Automotive Medicine. Injury Severity Scores (ISS) were calculated. Data pertaining to treatment and outcome was prospectively recorded by the trauma registry. The data (i.e. patient demographics, location of accident, details of resuscitation, injury characteristics and clinical outcomes) was reviewed and analysed after approval was obtained from the institutional review board. Patients were defined as an MT patient if they fulfilled any one of the following criteria: (a) an ISS $\geq 16$; (b) admitted to the intensive care unit; (c) had life- or limb-saving surgery; or (d) death. Those who did not fulfil the criteria were classified as non-major trauma (NMT) patients.

Statistical analysis was performed using IBM SPSS Statistics version 19.0 (IBM Corp, Armonk, NY, USA). Fisher's exact test was used for categorical variables, while Mann-Whitney $U$ test was used for nonparametric continuous variables. A p-value $<0.05$ indicated statistical significance.

\section{RESULTS}

From January 2011 to December 2013, a total of 261 children were admitted into KK Women's and Children's Hospital, Singapore, after being involved in RTAs as pedestrians. The majority of the children were male $(\mathrm{n}=158,60.5 \%)$ and primary-schoolers $(\mathrm{n}=131,50.2 \%)$. The median weight was 42.4 (range 8.6-93.7) kg

${ }^{1}$ Department of Paediatric Surgery, KK Women's and Children's Hospital, Singapore

Correspondence: Dr Chiang Li Wei, Consultant, Department of Paediatric Surgery, KK Women's and Children's Hospital, 100 Bukit Timah Road, Singapore 229899. chiang.li.wei@kkh.com.sg 
and the median age was 10 years (range 14 months-16 years). The demographics of these 261 children are shown in Table I.

The circumstances of the accidents are summarised in Table II. Most of the injuries sustained occurred on the road and in car parks. More than half of the accidents took place between $12 \mathrm{pm}$ and $6 \mathrm{pm}$. The majority of children were not accompanied by an adult at the time of the accident. Most of the accidents involved four-wheeled motor vehicles, followed by those that involved two- or three-wheeled motor vehicles.

Among the 261 injured children, 17 (6.5\%) children were classified as MT. Their clinical characteristics are shown in Table III. The median length of ICU admission was 5 (range 1-13) days, while the median length of hospital stay was 20 (range 1-51) days. The two patients who died were both aged two years and had an ISS of 16 and 38, respectively. Table IV shows the comparison of the children who were classified as MT and NMT. There was no statistically significant difference between the demographics of the two groups. When factors relating to the circumstances of the injuries were examined, only a positive history of being flung and loss of consciousness (LOC) demonstrated a statistically significant difference.

\section{DISCUSSION}

The demographics of the present patient cohort had several important characteristics. Echoing some previous reports, ${ }^{(3,7,8)}$ primary-schoolers were found to have the highest risk of being involved in an RTA as pedestrians. The authors of these reports cited parental misconception as the main contributing factor. In a survey conducted by Rivara et al, which involved 2,464 questionnaires, one-third of parents allowed preschoolers to cross quiet residential streets and primary-one children to walk to school alone. ${ }^{(7)}$ However, this is not supported by the policy statement on pedestrian safety from the American Academy of Paediatrics, which recommends that children younger than 10 years do not negotiate traffic conditions unsupervised, due to cognitive, perceptual and behavioural immaturities. In addition, the development of pedestrian skills varies widely among individuals; hence, older children may still be deficient in road safety skills. ${ }^{(4)}$ As the results of the present study showed that the majority of the pedestrian injuries involved children who were unaccompanied by an adult (i.e. $67.8 \%$ ), it is likely that the caregivers in our community share the same misconception.

In the present study, we also found that the majority of paediatric pedestrian injuries occurred between $12 \mathrm{pm}$ and $6 \mathrm{pm}$ after school hours, and on roadways. As most schools in Singapore conduct lessons in the morning, primary- and secondaryschoolers typically return home from school during the afternoon hours. We postulate that, although many children are escorted to school by their caregivers in the morning, they are generally expected to go home or to childcare facilities independently. The lack of supervision of these children in the afternoon could possibly lead to the peak injury timing of 12-6 pm. Agran et al compared the locations of 345 instances of pedestrian injury and found that a much higher incidence of accidents occurred
Table I. Demographic data of the children who were admitted for injuries due to their involvement in road traffic accidents as pedestrians $(n=261)$.

\begin{tabular}{lc}
\hline Variable & No. (\%) \\
\hline Gender & $158(60.5)$ \\
Male & $103(39.5)$ \\
Female & \\
Age group & $19(7.3)$ \\
Toddler (1-3 yr) & $44(16.9)$ \\
Pre-schooler (4-6 yr) & $131(50.2)$ \\
Primary-schooler (7-12 yr) & $67(25.7)$ \\
Secondary-schooler (13-16 yr) & \\
Weight (kg) & $3(1.1)$ \\
$<5$ & $15(5.7)$ \\
$5-10$ & $30(11.5)$ \\
$11-15$ & $28(10.7)$ \\
$16-20$ & $171(65.5)$ \\
$21-25$ & $14(5.4)$ \\
$>25$ &
\end{tabular}

Table II. Circumstances of road traffic accidents that involved children as pedestrians $(n=261)$.

\begin{tabular}{|c|c|}
\hline Variable & No. (\%) \\
\hline Not accompanied by an adult & $177(67.8)$ \\
\hline Toddler (1-3 yr) & $2(0.8)$ \\
\hline Pre-schooler (4-6 yr) & $15(5.7)$ \\
\hline Primary-schooler (7-12 yr) & $96(36.8)$ \\
\hline Secondary-schooler (13-16 yr) & $64(24.5)$ \\
\hline Accompanied by an adult & $84(32.2)$ \\
\hline Toddler (1-3 yr) & $17(6.5)$ \\
\hline Pre-schooler (4-6 yr) & $29(11.1)$ \\
\hline Primary-schooler (7-12 yr) & $35(13.4)$ \\
\hline Secondary-schooler (13-16 yr) & $3(1.1)$ \\
\hline \multicolumn{2}{|l|}{ Time of injury } \\
\hline $12 \mathrm{am}-6 \mathrm{am}$ & $4(1.5)$ \\
\hline $6 \mathrm{am}-12 \mathrm{pm}$ & $53(20.3)$ \\
\hline $12 \mathrm{pm}-6 \mathrm{pm}$ & $134(51.3)$ \\
\hline $6 \mathrm{pm}-12 \mathrm{am}$ & $63(24.1)$ \\
\hline Unknown & $7(2.7)$ \\
\hline \multicolumn{2}{|l|}{ Site of road traffic accident } \\
\hline Roadway & $212(81.2)$ \\
\hline Sidewalk & $17(6.5)$ \\
\hline Car park & $22(8.4)$ \\
\hline Others & $4(1.5)$ \\
\hline Unknown & $6(2.3)$ \\
\hline \multicolumn{2}{|l|}{ Vehicle type } \\
\hline 4-wheeled motor vehicle & $220(84.3)$ \\
\hline 2- or 3-wheeled motor vehicle & $30(11.5)$ \\
\hline Heavy vehicle & $6(2.3)$ \\
\hline Bicycle & $5(1.9)$ \\
\hline
\end{tabular}

on the streets (i.e. $81 \%$ ) than in off-road locations (i.e. 19\%). ${ }^{(9)}$ This finding is similar to that of the present study, highlighting that children are 'unreliable road users'. 
Table III. Clinical characteristics of the children with major trauma $(\mathbf{n}=17)$.

\begin{tabular}{lc}
\hline Clinical characteristic & No. (\%) \\
\hline Body region involved* & \\
Head & $14(82.4)$ \\
Face & $1(5.9)$ \\
Chest & $4(23.5)$ \\
Abdomen & $3(17.6)$ \\
Extremities & $7(41.2)$ \\
Injury Severity Score & \\
$<9$ & $1(5.9)$ \\
$9-15$ & $5(29.4)$ \\
$16-24$ & $4(23.5)$ \\
$\geq 25$ & $7(41.2)$ \\
Had limb- or life-saving surgery & $2(11.8)$ \\
Admitted to intensive care unit & $17(100.0)$ \\
\hline
\end{tabular}

*Note that more than one body region could have been injured in the accident.

Similar to previous reports, the present study had a low incidence of MTs (i.e. $6.5 \%$ of all paediatric pedestrian injuries). This raises the issue of whether clinicians have sufficient exposure to paediatric MT caseload and highlights the importance of a reliable triage system. Numerous paediatric trauma triage systems, incorporating both physiological parameters and injury mechanisms, have been proposed to identify children at risk for MT and to predict their outcomes. However, physiological parameters in children have been known to correlate poorly with injury severity. In addition, an earlier study from our institution, which evaluated the accuracy of the paediatric trauma score, Glasgow Coma Scale and respiratory rate in predicting MT, found that these factors demonstrated poor reliability. ${ }^{(10)}$ Kondo et al and Raux et al suggested that young age and a small body habitus were risk factors for MT. ${ }^{(11,12)}$ However, when we evaluated the correlation of MT with patient demographics and injury factors, we did not observe such a phenomenon. Moreover, no significant difference was detected between the MT and NMT groups in terms of demographic variables.

Although many trauma systems use the mechanism of injury as the criterion for prehospital bypass or activation of the trauma response team upon arrival, its poor reliability has been reported by many investigators. ${ }^{(13,14)}$ However, in the present study, a positive history of being flung and LOC showed a significant correlation with MT. This can be explained by the fact that a large amount of energy upon impact is required to fling the victim, thereby resulting in a more severe injury. Ivarsson et al reported that the most commonly injured body region in paediatric pedestrian injuries was the head and face. ${ }^{(15)}$ In our patient cohort, head injuries were the most common, isolated and severe injuries in paediatric traumas. ${ }^{(1)}$ We believe that this could be attributed to LOC, which we found to be an indicator for MT.

The results of the present study indicate that the group of children with the highest risk of being involved in an RTA as pedestrians in Singapore are primary-schoolers who return home from school unaccompanied in the afternoon. Future studies should evaluate parental attitudes, road traffic conditions and
Table IV. Comparison between the children with major trauma (MT) and those with non-major trauma (NMT).

\begin{tabular}{|c|c|c|c|}
\hline \multirow[t]{2}{*}{ Variable } & \multicolumn{2}{|c|}{ No. } & \multirow[t]{2}{*}{ p-value } \\
\hline & $\begin{array}{c}\text { MT } \\
(n=17)\end{array}$ & $\begin{array}{c}\text { NMT } \\
(n=244)\end{array}$ & \\
\hline Weight* $^{*}(\mathrm{~kg})$ & $\begin{array}{c}30.0 \\
(12.0-58.1)\end{array}$ & $\begin{array}{c}37.5 \\
(8.6-93.7)\end{array}$ & 0.176 \\
\hline Gender & & & 0.450 \\
\hline Male & 11 & 147 & \\
\hline Female & 6 & 97 & \\
\hline Age group & & & 0.900 \\
\hline Toddler (1-3 yr) & 3 & 16 & \\
\hline Pre-schooler (4-6 yr) & 2 & 42 & \\
\hline Primary-schooler (7-12 yr) & 11 & 120 & \\
\hline Secondary-schooler (13-16 yr) & 1 & 66 & \\
\hline Accompanied by an adult & & & 0.776 \\
\hline No & 11 & 166 & \\
\hline Yes & 6 & 78 & \\
\hline Time of injury & & & 0.178 \\
\hline $12 \mathrm{am}-6 \mathrm{am}$ & 1 & 3 & \\
\hline $6 \mathrm{am}-12 \mathrm{pm}$ & 1 & 52 & \\
\hline $12 \mathrm{pm}-6 \mathrm{pm}$ & 9 & 125 & \\
\hline $6 \mathrm{pm}-12$ am & 6 & 57 & \\
\hline Unknown & 0 & 7 & \\
\hline Site of road traffic accident & & & 0.764 \\
\hline Roadway & 14 & 198 & \\
\hline Sidewalk & 2 & 15 & \\
\hline Car park & 1 & 21 & \\
\hline Others & 0 & 4 & \\
\hline Unknown & 0 & 6 & \\
\hline Vehicle type & & & 0.426 \\
\hline 4-wheeled motor vehicle & 13 & 207 & \\
\hline 2- or 3-wheeled motor vehicle & 3 & 27 & \\
\hline Heavy vehicle & 1 & 5 & \\
\hline Bicycle & 0 & 5 & \\
\hline Flung & & & $0.001^{+}$ \\
\hline No & 8 & 199 & \\
\hline Yes & 9 & 45 & \\
\hline Loss of consciousness & & & $<0.001^{+}$ \\
\hline No & 11 & 229 & \\
\hline Yes & 6 & 15 & \\
\hline
\end{tabular}

*Data presented as median (range). + Statistically significant.

accident site geography. Clinicians treating paediatric pedestrian victims should be mindful that a positive history of being flung and LOC are predictors for MT.

\section{REFERENCES}

1. Chiang LW, Feng XYJ, Lin YC, Lee YT. The epidemiology and outcomes of paediatric trauma (poster). Singapore: Singapore Trauma Conference, 2013.

2. Agran PF, Winn DG, Anderson CL, Tran C, Del Valle CP. The role of the physical and traffic environment in child pedestrian injuries. Pediatrics 1996; 98(6 Pt 1):1096-103.

3. Braddock M, Lapidus G, Gregorio D, Kapp M, Banco L. Population, income, and ecological correlates of child pedestrian injury. Pediatrics $1991 ; 88: 1242-7$. 
4. Committee on Injury, Violence, and Poison Prevention; American Academy of Pediatrics. Policy statement--Pedestrian safety. Pediatrics 2009; 124:802-12.

5. Wazana A, Krueger P, Raina P, Chambers L. A review of risk factors for child pedestrian injuries: are they modifiable? Inj Prev 1997; 3:295-304.

6. DiMaggio C, Li G. Roadway characteristics and pediatric pedestrian injury. Epidemiol Rev 2012; 34:46-56.

7. Rivara FP, Bergman AB, Drake C. Parental attitudes and practices toward children as pedestrians. Pediatrics 1989; 84:1017-21.

8. Malek M, Guyer B, Lescohier I. The epidemiology and prevention of child predestrian injury. Accid Anal Prev 1990; 22:301-13.

9. Agran PF, Winn DG, Anderson CL. Differences in child pedestrian injury events by location. Pediatrics 1994; 93:284-8.

10. Lee YT, Feng XY, Lin YC, Chiang LW. Pediatric trauma team activation: are we making the right call? Eur J Pediatric Surg 2014; 24:46-50.

11. Kondo Y, Abe T, Kohshi K, et al. Revised trauma scoring system to predict in-hospital mortality in the emergency department: Glasgow Coma Scale, Age, and Systolic Blood Pressure score. Crit Care 2011; 15:R191.

12. Raux M, Sartorius D, Le Manach Y, et al. What do prehospital trauma scores predict besides mortality? J Trauma 2011; 71:754-9.

13. Williams D, Foglia R, Megison S, et al. Trauma activation: are we making the right call? A 3-year experience at a Level 1 pediatric trauma center. J Pediatr Surg 2011; 46:1985-91.

14. Balık E, Özok G, Ulman İ, Demircan M, Sakallı Ü. Pediatric trauma score: is it reliable in predicting mortality? Pediatr Surg Int 1993;8:54-5.

15. Ivarsson BJ, Crandall JR, Okamoto M. Influence of age-related stature on the frequency of body region injury and overall injury severity in child pedestrian casualties. Traffic Inj Prev 2006; 7:290-8. 